\title{
A generalized Damköhler number for classifying material processing in hydrological systems
}

\author{
C. E. Oldham ${ }^{1}$, D. E. Farrow ${ }^{2}$, and S. Peiffer ${ }^{3}$ \\ ${ }^{1}$ School of Environmental Systems Engineering, The University of Western Australia, 35 Stirling Hwy, \\ 6009 Crawley, Western Australia \\ ${ }^{2}$ Mathematics and Statistics, Murdoch University, 6150 Murdoch, Western Australia \\ ${ }^{3}$ Department of Hydrology, University of Bayreuth, Bayreuth, Germany \\ Correspondence to: C. E. Oldham (carolyn.oldham@uwa.edu.au), D. E. Farrow (d.farrow@murdoch.edu.au), \\ and S. Peiffer (s.peiffer@uni-bayreuth.de)
}

Received: 15 August 2012 - Published in Hydrol. Earth Syst. Sci. Discuss.: 18 September 2012

Revised: 1 February 2013 - Accepted: 17 February 2013 - Published: 15 March 2013

\begin{abstract}
Assessing the potential for transfer of pollutants and nutrients across catchments is of primary importance under changing land use and climate. Over the past decade the connectivity/disconnectivity dynamic of a catchment has been related to its potential to export material; however, we continue to use multiple definitions of connectivity, and most have focused strongly on physical (hydrological or hydraulic) connectivity. In contrast, this paper constantly focuses on the dynamic balance between transport and material transformation, and defines material connectivity as the effective transfer of material between elements of the hydrological cycle. The concept of exposure timescales is developed and used to define three distinct regimes: (i) which is hydrologically connected and transport is dominated by advection; (ii) which is hydrologically connected and transport is dominated by diffusion; and (iii) which is materially isolated. The ratio of exposure timescales to material processing timescales is presented as the non-dimensional number, $N_{\mathrm{E}}$, where $N_{\mathrm{E}}$ is reaction-specific and allows estimation of relevant spatial scales over which the reactions of interest take place. Case studies within each regime provide examples of how $N_{E}$ can be used to characterise systems according to their sensitivity to shifts in hydrology and gain insight into the biogeochemical processes that are signficant under the specified conditions. Finally, we explore the implications of the $N_{\mathrm{E}}$ framework for improved water management, and for our understanding of biodiversity, resilience and chemical competitiveness under specified conditions.
\end{abstract}

\section{Introduction}

Assessing the potential for export of nutrients and pollutants from catchments is of primary importance under changing land use and climatic conditions (Pringle, 2003a), yet our ability to predict export relies on a detailed understanding of both the transport and biogeochemical processing taking place (Hornberger et al., 2001). One of the challenges for the prediction of material transfer through catchments is the high degree of heterogeneity (of source distributions, transport media and biogeochemical processes), and its dependence on scale. Dooge (1986) suggested that scaling issues were fundamental to the development of hydrological theory, specifically the development of scaling relations across catchment scales and up-scaling from small-scale processes (Battiato and Tartakovsky, 2011). Since that time there has been substantial research on small-scale process-based distributed model descriptions, however the application of these models to large catchments has at times been problematic and the preferred modes of investigation continue to vary across scales (Table 1).

In response to this, McDonnell et al. (2007) challenged hydrologists to move "beyond heterogeneity and process complexity" to better facilitate the characterisation of catchments; however, approaches using either an ecological or hydrological lens tend to remain embedded in disciplinespecific process complexity. In a study that investigated interactions between vegetation and hydrology, Thompson et al. (2011b) highlighted the co-evolution of vegetation and 
Table 1. Different preferred modes of investigation used for different scales of elements in hydrological systems.

\begin{tabular}{|c|c|c|c|c|c|}
\hline & Soil pore scale & $\begin{array}{l}\text { Superficial } \\
\text { aquifer scale }\end{array}$ & Vegetation scale & Riparian scale & Catchment scale \\
\hline Vertical length scale & $O(\mathrm{~mm}-\mathrm{cm})$ & $O(\mathrm{~m}-10 \mathrm{~m})$ & $O(10 \mathrm{~cm}-1 \mathrm{~m})$ & $O(10 \mathrm{~cm}-1 \mathrm{~m})$ & $O(1-10 \mathrm{~m})$ \\
\hline Horizontal length scale & $O(\mathrm{~mm}-\mathrm{cm})$ & $O(10 \mathrm{~m}-100 \mathrm{~km})$ & $O(10 \mathrm{~cm}-1 \mathrm{~m})$ & $O(10-100 \mathrm{~m})$ & $O(10-1000 \mathrm{~km})$ \\
\hline Timescale & $O(\min )$ & $O$ (days-decades) & $O$ (min-seasons) & $O(\mathrm{~h}-\mathrm{yr})$ & $O$ (days-decades) \\
\hline Typical modes of investigation & Laboratory/numerical & Numerical/field & Laboratory/field & Field/numerical & Numerical/field \\
\hline
\end{tabular}

hydrological spatial organization, yet continued to use a hydrological lens, via a water balance approach, to characterise systems across scales. An alternative approach is to adopt a dual lens, in which the focus remains on the dynamic balance between hydrological and ecological processes. A single lens approach assumes the ecosystem responds to hydrological forcing; a dual lens approach assumes the ecosystem responds to shifts in the balance between hydrological and ecological processes. The range of ecological processes of relevance to catchment studies is vast; hereon we focus on material fate as expressed by biogeochemical reactions.

In an attempt to identify parameters that resolved the "scale" issue, Vaché and McDonnell (2006) flagged that water residence times were integrative and meaningful across all scales, and went on to highlight the challenges in characterising flow paths, and therefore residence times, that were of relevance to material transport; the residence time is a critical parameter within the dual lens approach. The residence time distribution (RTD) has been used as fundamental characteristic of aquatic systems with free surfaces (Carleton, 2002; Werner and Kadlec, 2000) and more recently of catchments (Beven, 2001; McDonnell et al., 2010; McGuire and McDonnell, 2006). Botter et al. (2011) highlighted the difference between the probability density function (pdf) of water parcel travel/transit time within a catchment, and the pdf of catchment residence times. They also noted the temporal variability of these pdfs as a function of meteorological and hydrological forcing (Botter et al., 2010; Hrachowitz et al., 2010). All of these authors noted the importance of the residence and transit times, or their distributions, for the export of pollutants and nutrients from catchments, and recently, Basu et al. (2011a,b) explored the relationships between pdfs and pollutant and nutrient export from catchments, whereas Thompson et al. (2011a) used ratios of the coefficients of variation of chemical concentration and discharge to classify chemical export from catchments.

Estimates of characteristic residence times have been used in dimensionless ratios (Carleton, 2002; Hornberger et al., 2001; Ocampo et al., 2006) to improve our understanding of catchment hydro-chemical responses and chemical cycling. The dimensionless Damköhler number, $D a$, has been used extensively in the discipline of chemical engineering to classify a system according to the balance between transport and reaction, and is given as

$$
D a=\frac{\tau_{\mathrm{T}}}{\tau_{\mathrm{R}}}
$$

where $\tau_{\mathrm{T}}$ is the transport (or residence) timescale and $\tau_{\mathrm{R}}$ is the reaction timescale. Thus, $D a$ can be considered an important non-dimensional number within the dual lens approach.

Michalak and Kitanidis (2000) used Da to characterise the appearance of chemical sorption peaks in simulation experiments. Wehrer and Totsche (2003) used Da to characterise when breakthrough of contaminants took place under nonequilibrium conditions, Ocampo et al. (2006) explored the removal of nitrate by riparian zones and demonstrated that $50 \%$ nitrate removal occurred when $D a<1$ and increased to nearly $100 \%$ at $D a=2-20$. Kurtz and Peiffer (2011) demonstrated that surface complexation needs to be considered to explain the increase of $\mathrm{FeOOH}$ turnover rates, by dissolved S (II), with increasing $D a$ numbers. Battiatoc and Tartakovsky (2011) used $D a$ in combination with multiple scale expansions to upscale from micro (pore) scale reactiondiffusion-advection processes to derive macro (averaged) governing equations.

The residence time distributions, as explored by Botter et al. (2011), create a Damköhler number distribution (DND) for a given aquatic system and Carleton (2002) explored the relationship between RTD and the DND in a wetland treatment system. In an exploration of hydrological versus biogeochemical controls, Basu et al. (2011b) used ratios of transport to reaction timescales to characterise nutrient and pollutant export from agricultural catchments. While Basu et al. (2011b) did not specifically define their regimes in terms of $D a$, their approach is similar. Given that the $D a$ and the DND have been successfully used to characterise the transfer of material under a range of transport conditions and across a range of spatial scales from pores to wetlands and riparian zones, we suggest that $D a$ could be used to characterise hydrological elements in a catchment. We note, however, that by definition the use of $D a$ assumes hydrological (or hydraulic) connectivity.

The hydrological connectivity/disconnectivity dynamic is a key characteristic of many catchments (Meerkerk et al., 2009; Michaelides and Chappell, 2009; Ocampo et al., 2006; Pringle, 2003a,b) and is considered critical for ecological function, adaptation and evolution (Klein et al., 2009; Opperman et al., 2010; Pringle, 2003b). Over the past decade there have been numerous attempts to characterise 
the connectivity/disonnectivity dynamic (Ali and Roy, 2010; Meerkerk et al., 2009; Michaelides and Chappell, 2009; Tetzlaff et al., 2007). Pringle (2003b) noted the variety of definitions of connectivity, used across and within disciplines. In recent years, a commonly used definition is the ability of energy, matter and organisms to transfer within and between elements (for example sub-catchments, riparian zones, wetlands, streams) of the hydrologic cycle (Detty and McGuire, 2010; Pringle, 2003b). We note the historical tendency to define connectivity in terms of water movement, i.e. hydrological or hydraulic connectivity, however under this definition quantifying the threshold of hydrological disconnectivity remains problematic. Are hydrological elements that are partially or fully saturated (with water) considered connected? Does hydrological connectivity imply transport between hydrological elements? If so, is there a minimum transit time between hydrological elements, below which the elements are considered disconnected? Hydrological connectivity, within these contexts and across different scales, is thus operationally defined.

Additional complexity arises when we are interested in the fate of reactive material being transferred across hydrologically connected landscapes. To our knowledge there have been no attempts in the hydrological literature to characterise connectivity in terms of the effectiveness of transferring material. Such a characteristic might be termed "material connectivity" and must take into account both the hydrological/hydraulic transport and the biological and/or chemical fate or processing; such a definition is needed under a dual lens approach. Multiple elements of the hydrological cycle may be fully connected hydrologically, yet if material is being removed, or settles under gravity, the material transfer between elements is not effective, so by our definition above, the material connectivity between those elements is poor. The effectiveness of material connectivity is a critical parameter for ecological processes and outcomes.

To illustrate our point we present two examples. Firstly, we take the example of Fe(II)-rich anoxic groundwaters being discharged into a well-oxygenated stream which then flows into a lake. The groundwater, stream and lake are hydrologically and hydraulically fully connected; however, Fe(II) undergoes oxidation on exposure to oxygenated waters, and likely precipitates as $\mathrm{Fe}$ (III)-oxide, which may affect the benthic ecology. The balance between the rate of transport, the rate of $\mathrm{Fe}$ (II) oxidation, the rate of precipitation and settling, and the rate of $\mathrm{Fe}(\mathrm{II})$ production from reductive dissolution will determine the effectiveness of material connectivity, with respect to $\mathrm{Fe}(\mathrm{II})$, between the groundwater and lake. If all $\mathrm{Fe}$ (II) is oxidized before reaching the lake, the systems are materially disconnected with respect to $\mathrm{Fe}(\mathrm{II})$. Under this scenario, the reaction timescale (oxidation, precipitation and settling) is much shorter that the transport timescale, $D a \gg 1$, ensuring material disconnectivity even under hydrologically connected conditions. Secondly, we take the example of a phytoplankton-rich wetland under flooding conditions, being flushed out across a floodplain and into a lake. The wetland, the floodplain and the lake are hydraulically connected, however in transit the phytoplankton may grow, aggregate, settle and decompose. The balance between the rate of transport, the rate of particle settling under gravity and the phytoplankton net productivity will determine the extent of material connectivity, with respect to the phytoplankton, between the wetland and the lake. If all phytoplankton settle out (or decompose) before reaching the lake, the lake and wetland are materially disconnected with respect to phytoplankton. Under this scenario, the reaction timescale (settling and decomposition) is much shorter that the transport timescale, $D a \gg 1$, ensuring material disconnectivity even under hydraulically connected conditions.

We note that in the two examples provided above, hydrological or hydraulic connectivity is preserved, $D a$ is defined and therefore material connectivity can be estimated. When systems are no longer hydrological/hydraulically connected, $D a$ is no longer defined, yet intermittent hydrological connectivity/disconnectivity characterises many ecosystems. This paper explores the extension of the $D a$ framework to conceptually characterise hydrological systems, including systems undergoing intermittent connectivity, and thus to provide insights into processes controlling the export of material from catchments. To populate this framework, we provide examples where a standard Da approach may be used (i.e. under hydrological connectivity) but use the nondimensional Peclet number to determine appropriate length and timescales. We also provide examples of disconnected systems where a new non-dimensional number must be defined. For clarity, we modify the broader connectivity definition of Pringle (2003b) to a definition of material connectivity as the ability of material to transfer between elements of the hydrologic cycle, while subject to biogeochemical or biological processing.

\section{Conceptual framework}

\subsection{Governing equations}

We have defined material connectivity as the ability to transfer matter between hydrological elements. We therefore begin the development of our framework with the scalar transport equation, or advection-diffusion-reaction (ADR) equation, that describes transport of chemical $B$ via a homogeneous fluid (constant density and viscosity) which is given as

$$
\frac{\partial[B]}{\partial t}=-u_{i} \frac{\partial[B]}{\partial x_{i}}+D_{\text {eff }} \frac{\partial^{2}[B]}{\partial x_{i} \partial x_{i}}-k^{\prime}[B]
$$

where $[B]$ is the concentration of chemical $B\left(\mathrm{mmol} \mathrm{m}^{-3}\right)$, $u_{i}$ is the mean velocity in the $i$-direction $\left(\mathrm{m} \mathrm{s}^{-1}\right), t$ is time (s), $x_{i}$ is distance in the $i$-direction (m), $D_{\text {eff }}$ is the effective diffusion/dispersion coefficient $\left(\mathrm{m}^{2} \mathrm{~s}^{-1}\right)$ and $k^{\prime}$ is an appropriate 
rate constant $\left(\mathrm{s}^{-1}\right)$. Outside of diffusive boundary layers, $D_{\text {eff }}$ is likely to be significantly larger than molecular diffusivity and is a simplified but commonly used description of stochastic processes such as turbulent diffusion, bioturbation or mechanical dispersion (Bolster et al., 2012; Cirpka and Attinger, 2003). Term I describes advective transport of chemical $B$, Term II describes Fickian transport of chemical $B$, and Term III describes the rate at which chemical $B$ is consumed.

We apply Eq. (2) to an idealized one-dimensional control volume or hydrological element that has a physically constrained horizontal length scale of $\Delta x$ and a through-flow velocity $u_{x}$. The general solution to Eq. (2) is then

$$
\begin{aligned}
{[B] } & =\exp \left(-k^{\prime} t\right)\left[\alpha_{0}+\sum_{n=0}^{\infty}\left(\alpha_{n} \cos \left(\frac{n \pi}{\Delta x}\left(x-u_{x} t\right)\right)\right.\right. \\
& \left.\left.+\beta_{n} \sin \left(\frac{n \pi}{\Delta x}\left(x-u_{x} t\right)\right)\right) \exp \left(-\frac{n^{2} \pi^{2} D_{\text {eff }}}{\Delta x^{2}} t\right)\right]
\end{aligned}
$$

where $n$ is the summation index and $\alpha_{n}$ and $\beta_{n}$ are Fourier cosine and sine coefficients, respectively, which are determined by the initial and boundary conditions that apply to the particular element being modelled.

\subsection{Timescales}

\subsubsection{Exposure timescales}

Most authors have defined connectivity as a hydrological or hydraulic continuum and the transport timescales are derived from this definition. However, in many environments there are times when elements of the hydrological cycle are hydrologically, hydraulically or materially disconnected or isolated. We have defined material connectivity as the ability to transfer matter between hydrological elements; however, it is important to consider that during periods of isolation, material processing can continue within an hydrological element and material will accumulate or decline, creating an isolated material reactor in the environment. One of our objectives is to develop a framework that encompasses both periods of connectivity and isolation, making a clear distinction between hydrological versus material connectivity.

To facilitate this objective, we now conceptually define an exposure timescale, $\tau_{\mathrm{E}}$, as the timescale over which material has the opportunity to be processed. This opportunity may occur during transport (i.e. when elements are hydrologically connected) or during hydrological disconnection. The concept of an exposure timescale has been previously used in surface renewal theory (Dankwerts, 1951) and chemical engineering (Asarita, 1967). We stress here the distinction between the commonly used transport timescale (defined only during periods of hydrological connection) and the exposure timescale (defined during both hydrological connection and isolation). The exposure timescale is used to describe the transit time between elements, or the isolation timescale of an

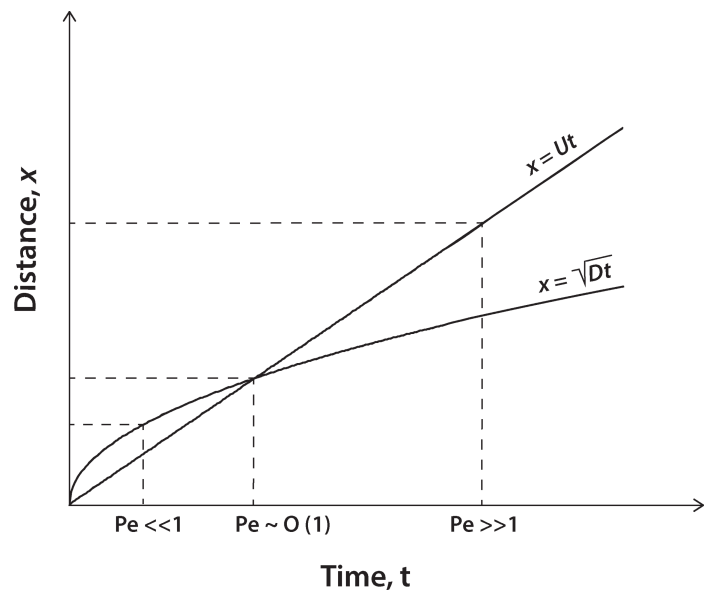

Fig. 1. The relationship between characteristic length, $x$, and time, $t$, scales under varying Peclet number conditions. Under $P e \gg 1$, advective processes dominate (Regime I); under $P e \ll 1$ diffusive processes dominate (Regime II); when $P e \sim \mathrm{O}(1)$, the characteristic length and timescales are set where the advection and diffusive lines intersect.

individual element. Both timescales provide opportunity for exposure. Averaging of transit and isolation timescales may provide an "effective" exposure timescale, however biogeochemical processes are frequently different under connected versus disconnected conditions. If we are aiming to extend the Da approach, it is critical that the relevant biogeochemical processes are identified for each condition and thus temporal averaging across conditions may not be appropriate.

The choice of appropriate control volume determines relevant time and length scales as well as boundary conditions and thus becomes critical for application of our governing equations. An initial assumption is that the control volume and therefore the characteristic length scale, $\Delta x_{i}$, are physically constrained, typically by geomorphology (for example by the catchment, stream or wetland). The sizes of hydrologically isolated systems are by definition physically constrained.

For hydrologically connected systems, the relevant exposure timescale, $\tau_{\mathrm{E}}$, is then determined by the length scale and the transport process (Fig. 1). Note that exposure length scales can be highly variable between individual flow paths and require an appropriate definition of the hydrological problem. In many cases it may be convenient to use a mean length scale for a specific system. When a control volume is not physically constrained, it may be defined operationally, depending on the objectives; an example of this approach is given in Sect. 2.3.

The exposure timescale for hydrologically connected elements under advective conditions is then given as

$$
\tau_{\mathrm{E}}^{\mathrm{A}}=\frac{\Delta x}{u_{x}} .
$$



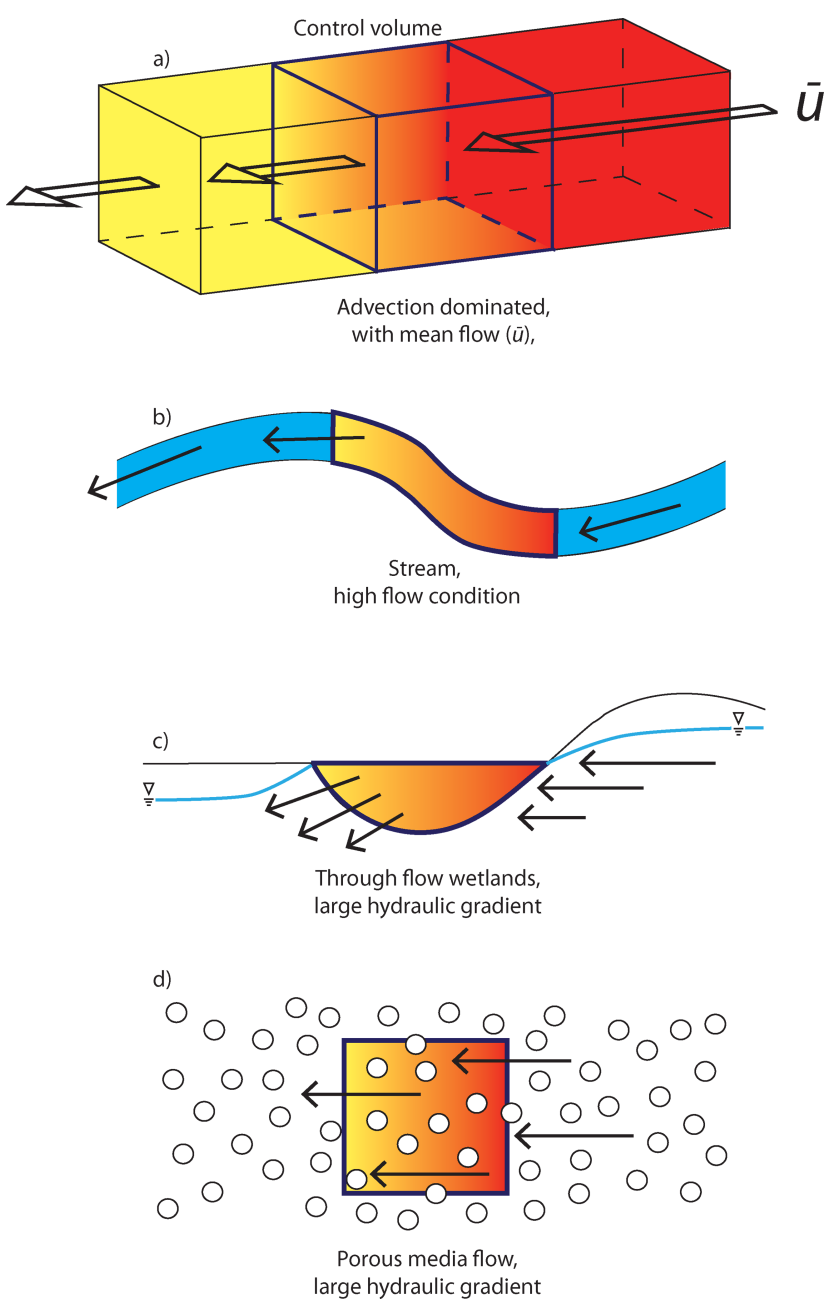

Fig. 2. Regime I: (a) transport and fluxes of chemical $B$ across hydrologically or hydraulically connected elements are dominated by advection. Examples of this regime are a river under high flow conditions (b), a wetland with groundwater throughflow under a large hydraulic gradient (c) and porous media flow under a large hydraulic gradient (d).

Examples of aquatic systems that are dominated by advective transport are shown in Fig. 2.

The exposure timescale for hydrologically connected elements under diffusive conditions, is given as

$\tau_{\mathrm{E}}^{\mathrm{D}}=\frac{\Delta x_{i}^{2}}{D_{\text {eff }}}$.

Examples of aquatic systems that are dominated by diffusive transport are shown in Fig. 3. We note that exposure timescales may be defined differently by stochastic transport models; any carefully formulated definition may be utilized in the framework.

When hydrological elements are materially disconnected or isolated, the exposure timescale in the isolated element is equivalent to the isolation timescale, $\tau_{\mathrm{E}}^{\mathrm{I}}$. If the element
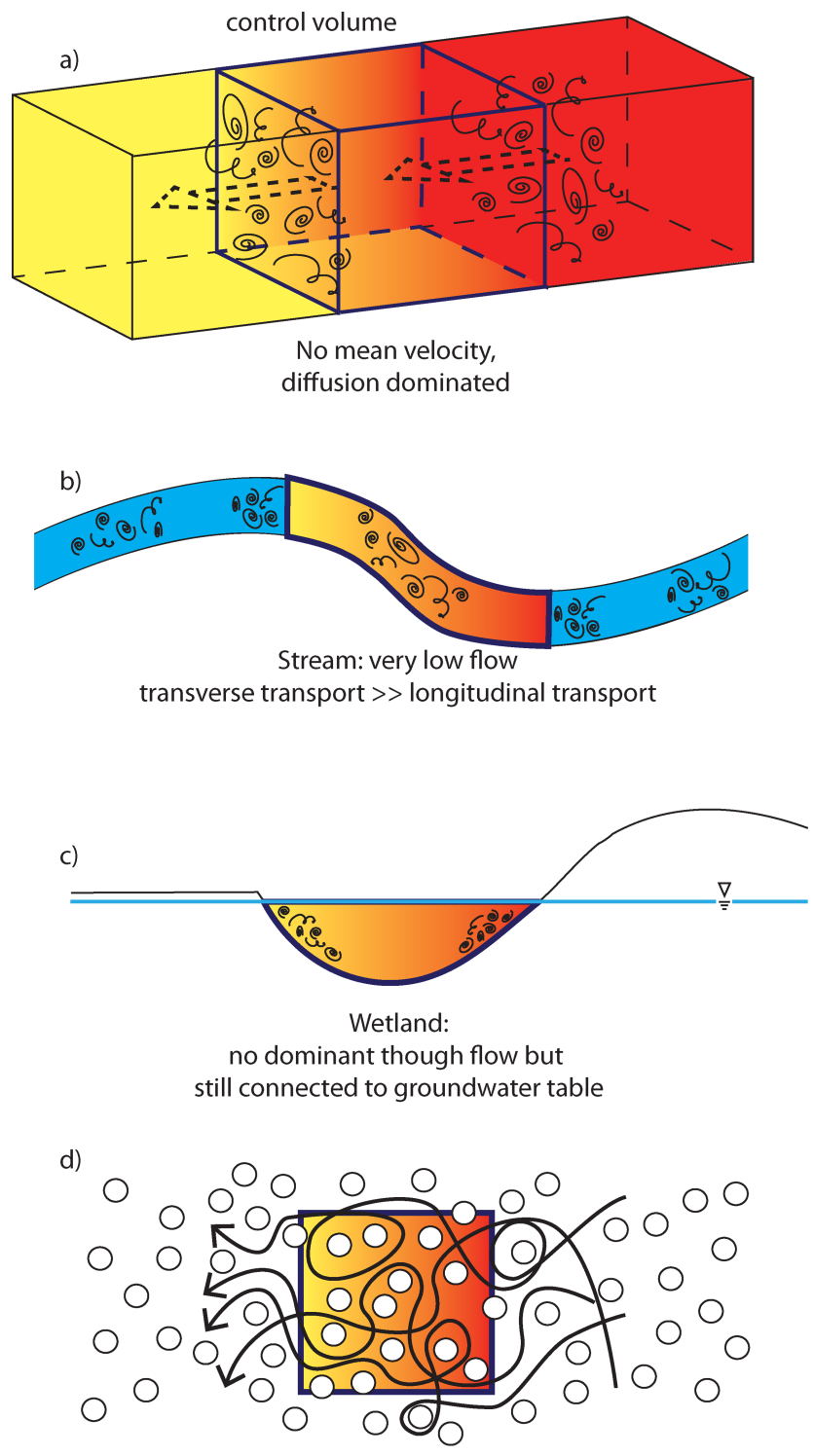

Porous media flow:

saturated but minimal hydraulic gradient, diffusion dominated

Fig. 3. Regime II: (a) transport and fluxes of chemical $B$ across hydrologically or hydraulically connected elements are dominated by diffusion. Examples of this regime are a river under very low flow conditions, where for example transverse transport exceeds longitudinal transport (b), a wetland at equilibrium with the local groundwater (c) and porous media flow under minimal hydraulic gradient (d).

undergoes periodic connection and disconnection (for example on an annual basis), $\tau_{\mathrm{E}}^{\mathrm{I}}$ is related to the connection or disturbance frequency, $k_{\mathrm{D}}$, a concept used extensively in terrestrial ecology (Huston, 1994). Probability density functions can be used to characterise repeated stochastic events (e.g. flooding, fire, rainfall) and the periods between events, providing quantification of $\tau_{\mathrm{E}}^{\mathrm{I}}$ distributions. 
We stress again that isolation may be defined both hydrologically and materially. As commented above, connectivity (and therefore isolation) has previously been defined based on hydrology. When water flows between elements, they are hydrologically connected. When water no longer flows between elements, they are hydrologically isolated. However, if material is consumed or settled prior to reaching the adjacent element, material isolation of elements is possible even during hydrological connectivity. For material isolation, the efficiency of material transfer will be poor. Our definition of "poor material transfer" is arbitrary and will vary with application. In some contexts, a $50 \%$ transfer of material between elements may define them as materially isolated. In other applications, $1 \%$ material transfer between elements may define isolation. Examples of aquatic systems that are materially isolated are shown in Fig. 4.

\subsubsection{Material processing timescales}

Term III in Eq. (2) contains a rate constant for material processing, such as chemical reaction, seed dispersal and recruitment, nutrient uptake, biogeochemical cycling, etc. We continue below with a focus on biogeochemical cycling. While acknowledging that many biogeochemical processes have more complex kinetics, we initially assume our chemical reaction of interest can be described as

$A+B \stackrel{k}{\longrightarrow} C+D$.

Equation (6) can be treated as a second order reaction where $k$ is the second order rate constant $\left(\mathrm{m}^{3} \mathrm{mmol}^{-1} \mathrm{~s}^{-1}\right)$. But if we assume $A$ to be in excess of $B$, then Eq. (6) can be considered "pseudo-first-order" with respect to $B$, where $[B]$ is not limiting and

$\frac{\mathrm{d}[B]}{\mathrm{d} t}=-k^{\prime}[B]$,

where $k^{\prime}$ is the pseudo-first-order rate constant $\left(\mathrm{s}^{-1}\right)$ and is used in Eq. (2). The material (in this case chemical) processing timescale is then

$\tau_{\mathrm{P}}=1 / k^{\prime}$.

For reactions mediated by microbes and enzymes, we can use a Monod kinetic model (Park and Jaffe, 1995; Schäfer et al., 1998), which describes the rate of microbial growth as a function of substrate concentration:

$\frac{\mathrm{d}[X]}{\mathrm{d} t}=\mu_{\max } \frac{[B]}{K_{\mathrm{s}}+[B]}[X]$,

where $\mu_{\max }$ is the maximum specific growth rate $\left(\right.$ day $\left.^{-1}\right)$, $[X]$ is the concentration of cells (cells $\mathrm{L}^{-1}$ ) and $K_{\mathrm{S}}$ is the substrate half-saturation constant $\left(\mathrm{mmol} \mathrm{L}^{-1}\right)$. The corresponding equation for the rate of substrate consumption is

$\frac{\mathrm{d}[B]}{\mathrm{d} t}=-q_{\max } \frac{[B]}{K_{\mathrm{s}}+[B]}[X]$

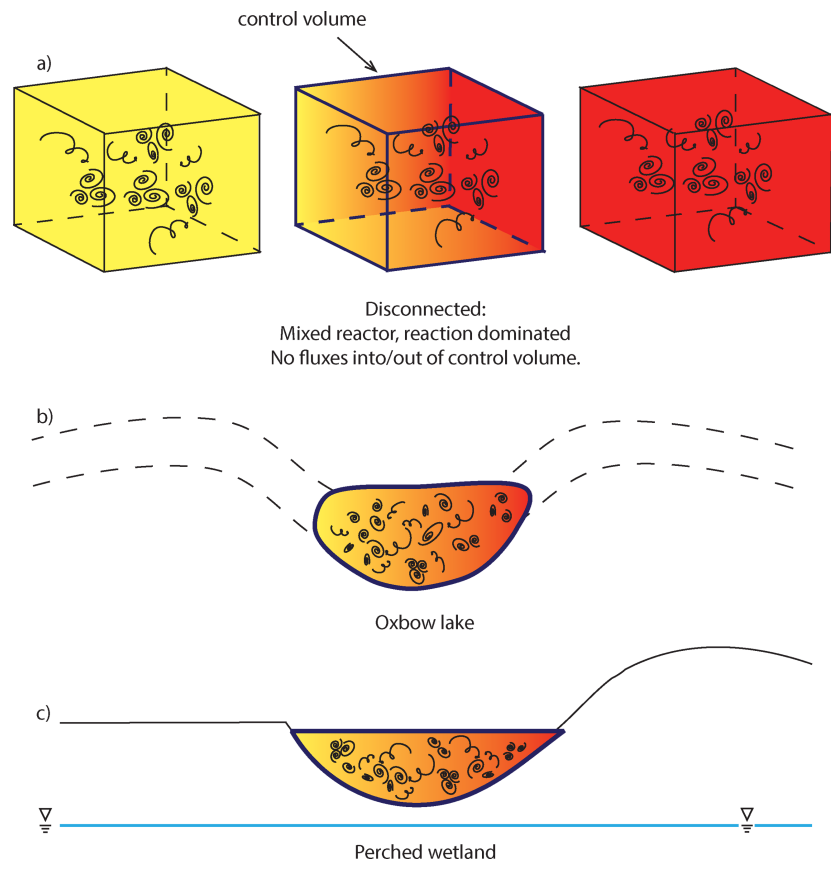

Fig. 4. Regime III: (a) the elements of interest are hydrologically and hydraulically disconnected. Examples of this regime are an oxbow lake, which has disconnected from its river (b), and a wetland perched above the groundwater table (c).

where $q_{\max }$ is the maximum specific consumption rate $\left(\right.$ mmol cell ${ }^{-1}$ day $\left.^{-1}\right)$ and

$q_{\max }=\mu_{\max } Y$,

where $Y$ is the cell yield $\left(\mathrm{mmol} \mathrm{cell}^{-1}\right)$. We define the characteristic timescale as being the time at which $[B]=\mathrm{K}_{\mathrm{s}}$ and thus

$\tau_{\mathrm{P}}=\frac{2}{\mu_{\max }}$.

Note that processing timescales are intrinsic timescales derived from rate laws describing reactions taking place at the scale of the reactants (e.g. microorganisms, microbial consortia, biofilms, mineral surfaces) with full access to substrate or under conditions of complete mixing. Under conditions where short exposure timescales constrain access to substrate and/or reaction, the effective processing timescales may be significantly longer than intrinsic timescales (and hence, under 1st order conditions, effective rate constants will be less that intrinsic rate constants). Careful analysis is required to clarify whether intrinsic or effective processing timescales are desirable or useful to a specific problem; the use of effective processing timescales may remove the signature of key drivers of a system.

\subsection{Non-dimensional numbers}

Non-dimensional numbers have long been used to characterise natural and built systems; some common examples are 
the Mach number, the Reynolds number and the hydraulic gradient. Battiato and Tartakovsky (2011) proposed the use of non-dimensional numbers in hydrological upscaling approaches and to provide quantitative measures of the validity of upscaling approximations. We now explore two nondimensional variables that make up the key components of our connectivity framework.

The non-dimensional Peclet number, $P e$, provides the balance between advection and diffusion under hydrological connectivity as

$P e=\frac{\tau_{\mathrm{E}}^{\mathrm{D}}}{\tau_{\mathrm{E}}^{\mathrm{A}}}=\frac{u_{i} \Delta x_{i}}{D_{\mathrm{eff}}}$,

where $\Delta x_{i}$ is the characteristic length scale over which transport processes are operating. The $P e$ is used to determine whether Terms I or II in Eq. (2) are retained.

The Damköhler number (Eq. 1) has been used extensively in chemical engineering and more recently in environmental and hydrological contexts. However, the definition of $D a$ implicitly assumes hydrological or hydraulic connectivity. Without hydrological connectivity, there is no transport of chemicals between hydrological elements, therefore we are unable to define $\tau_{\mathrm{T}}$. For example, $D a$ could not be used to characterise hydrologically disconnected systems that are defined by the isolation timescale $\tau_{\mathrm{E}}^{\mathrm{I}}$.

To characterise material fate during both hydrological connection and disconnection, we propose the use of the more general form

$N_{\mathrm{E}}=\frac{\tau_{\mathrm{E}}}{\tau_{\mathrm{P}}}$

where $\tau_{\mathrm{E}}$ is the generalized exposure timescale, $\tau_{\mathrm{P}}$ is a generalized processing timescale, and $N_{\mathrm{E}}$ gives an indication of the extent of material processing possible within the exposure timescale. For hydrologically connected elements, when $N_{\mathrm{E}} \ll 1$, material is transferred conservatively between elements; when $N_{\mathrm{E}} \gg 1$, material will have plenty of opportunity to be processed within the exposure times. For a hydrologically isolated element, when $N_{\mathrm{E}} \ll 1$, material is unlikely to be processed while that element is isolated; when $N_{\mathrm{E}} \gg 1$, material will be processed during isolation.

For systems that are intermittently connected, we suggest separate estimation of $N_{\mathrm{E}}$ for the connected and disconnected conditions. This forces us to define exposure and processing timescales for both conditions, allows assessment of the ecological significance of each condition (is the isolated state more significant? or is it the connected state that is important for the system? or both?) and facilitates decisions on appropriate spatial or temporal averaging of exposure timescales. Even if the isolation timescale $\ll$ the transport timescale, their relevance for material connectivity depends on $N_{\mathrm{E}}$. If $N_{\mathrm{E}} \gg 1$ during isolation, and $N_{\mathrm{E}} \ll 1$ during transport, then the isolation period will be ecologically relevant even if it is shorter than the subsequent transport timescale. A priori averaging to obtain an "effective" exposure timescale may in fact remove critical information about fundamental controls on the ecosystem.

There are times when the length scale of a control volume is not physically constrained, instead the physical dimensions of the control volume may be arbitrarily sized to ensure, for example, that $90 \%$ of material of interest within the control volume is processed. If we take an example of a pseudo-firstorder reaction occurring across a hydrologically connected system, and using Eq. (13), then Eq. (7) can be integrated to obtain

$$
\begin{aligned}
{[B]_{*} } & =[B]_{0} \exp \left(-k^{\prime} \tau_{\mathrm{E}}\right) \\
& =[B]_{0} \exp \left(-N_{\mathrm{E}}\right)
\end{aligned}
$$

where $[B]_{*}$ is $[B]$ at $t=\tau_{\mathrm{E}}$ and $[B]_{0}$ is $[B]$ at $t=0$.

When chemical $B$ is $90 \%$ removed,

$\frac{[B]_{*}}{[B]_{0}}=0.1=\exp \left(-N_{\mathrm{E}}\right)$,

then $N_{\mathrm{E}} \sim 2.3$. So for a system where $N_{\mathrm{E}} \gg 2.3$, we expect more than $90 \%$ removal of chemical. For a system where $N_{\mathrm{E}} \ll 2.3$, we expect less than $90 \%$ removal of chemical. This framework also has application for the definition of materially isolated systems and highlights that material isolation is a function of $N_{\mathrm{E}}$, rather than an absolute concept.

Examples of the use of $N_{\mathrm{E}}$ for specific contexts are presented below and as case studies in the discussion. The definition of boundary and initial conditions are required as the framework is applied, and their magnitude and character (e.g. constant or varying with time) will depend on application. This is analogous to the application of the nondimensional Reynolds number, $R e$, which describes the balance between inertial and viscous forces and is used to characterise environmental flows. $R e$ is defined by the context or application, requiring careful definition of the system, its relevant length scales, and thus velocities. These velocities may be estimated via order of magnitude estimates, via experimental data or via complex numerical modeling. The scaledependent $R e$ provides a framework for conceptualizing a problem and provides a degree of generalization across systems. We envisage a similar utility of $N_{\mathrm{E}}$.

\subsection{Special cases}

\subsubsection{Regime I: advection dominated}

For systems that are hydraulically or hydrologically connected and $P e \gg 1$, i.e. the system is advection dominated (Fig. 2), Term II in Eq. (2) drops out, leaving

$$
\frac{\partial[B]}{\partial t}=u_{i} \frac{\partial[B]}{\partial x_{i}}-k^{\prime}[B] .
$$

Substituting Eq. (4) and $k^{\prime}$ into Eq. (13) gives

$N_{\mathrm{E}}^{\mathrm{A}}=\frac{\tau_{\mathrm{E}}}{\tau_{\mathrm{P}}}=\frac{k^{\prime} \Delta x}{u_{x}}$. 
When $N_{\mathrm{E}} \gg 1, \tau_{\mathrm{E}} \gg \tau_{\mathrm{P}}$, which indicates that the control volume exposure time is sufficiently long for chemicals $A$ and $B$ to react. When $N_{\mathrm{E}} \ll 1, \tau_{\mathrm{T}} \ll \tau_{\mathrm{P}}$, which indicates that chemicals $A$ and $B$ do not have sufficient time to react before they are advected out of the control volume; in this case chemicals $A$ and $B$ may be treated as if they are conservative.

In the large $P e$ limit, the general solution Eq. (3) can be re-written as

$[B]=\exp \left(-k^{\prime} t\right) f\left(x-u_{x} t\right)$

where the function $f(x)$ represents the initial $(t=0)$ distribution of $[B]$ in the element. As time increases, the initial profile of $[B]$ is advected at speed $u_{x}$ between the elements with a reduction in magnitude due to the reaction term.

This solution and its behaviour are shown in Fig. 5a and b. Figure 5a shows the case where there is no significant consumption of $B\left(N_{\mathrm{E}} \ll 1\right)$ before it has been advected between the elements. The magnitude of the initial profile has been preserved. Figure $5 \mathrm{~b}$ shows a reduction in the magnitude of the profile due to significant consumption of $B\left(N_{\mathrm{E}} \gg 1\right)$. Note, however, that $B$ has not spread during transport between the elements since this is the advection-dominated regime (i.e. diffusion is minimal).

\subsubsection{Regime II: diffusion dominated}

For systems that are hydraulically or hydrologically connected and $P e \ll 1$ (i.e. system is diffusion dominated, Fig. 3), Term I in Eq. (2) drops out; so we have

$$
\frac{\partial[B]}{\partial t}=D_{\text {eff }} \frac{\partial^{2}[B]}{\partial x_{i} \partial x_{i}}-k^{\prime}[B],
$$

and given Eq. (5), then

$N_{\mathrm{E}}^{\mathrm{D}}=\frac{k^{\prime} \Delta x^{2}}{D_{\mathrm{eff}}}$

When $P e \ll 1$, the general solution Eq. (3) can be re-written as

$$
\begin{aligned}
{[B] } & =\exp \left(-k^{\prime} t\right)\left[\alpha_{0}+\sum_{n=0}^{\infty}\left(\alpha_{n} \cos \left(\frac{n \pi}{\Delta x_{i}} x\right)\right.\right. \\
& \left.\left.+\beta_{n} \sin \left(\frac{n \pi}{\Delta x_{i}} x\right)\right) \exp \left(-\frac{n^{2} \pi^{2} D_{\text {eff }}}{\Delta x_{i}^{2}} t\right)\right] .
\end{aligned}
$$

In the absence of significant reaction $\left(N_{\mathrm{E}} \ll 1\right), B$ will eventually diffuse through the entire system without significant loss of $B$. This is shown in Fig. 5c. Alternatively, if $N_{\mathrm{E}} \gg 1$, then much of $B$ will be used up before it has a chance to diffuse through the system, which is shown in Fig. 5d.

The idealized solutions discussed above for Regimes I and II have assumed some initial distribution of $[B]$ and periodic boundary conditions. More general boundary conditions (for example fixed flux or fixed concentration boundary
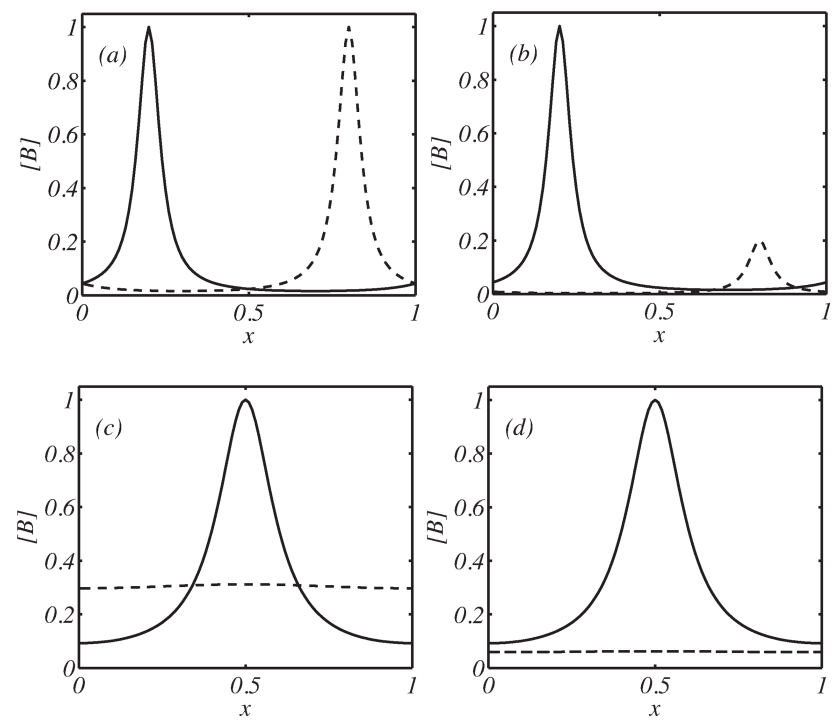

Fig. 5. Example profiles of $[B]$ from the model problem for small (solid line) and large (dashed line) times illustrating the evolution of [B] under different conditions: (a) $P e \gg 1$ and NE $\ll 1$, (b) $P e \gg 1$ and NE $\gg 1$, (c) $P e \ll 1$ and NE $\ll 1$, (d) $P e \ll 1$ and NE $\gg 1$. Note that in this figure, $B$ and $x$ have been normalized for illustrative purposes.

conditions) do not affect the general framework and regimes outlined above. The fate of inflows at the boundaries of the element is determined by the element's regime.

\subsubsection{Regime I and II boundary}

We have shown how to use $P e$ and $N_{\mathrm{E}}$ to characterise hydrological systems, however porous media are frequently characterised by their dispersivity,

$\alpha_{i}=\frac{D_{\text {eff }}}{u_{i}}$.

If we normalize the dispersivity by the characteristic length scale (i.e. the length of the control volume), then

$\frac{\alpha_{i}}{\Delta x_{i}}=\frac{D_{\text {eff }}}{u_{i} \Delta x_{i}}=\frac{1}{P e}$.

Note that this relationship is dependent on scale and the empirically derived relationship

$\alpha_{i}=0.0175 \Delta x_{i}^{1.46}$

can be applied to a flow path length less than $3500 \mathrm{~m}$ (Todd and Mays, 2005).

Reported horizontal field dispersivities considered of high reliability, typically range from $10^{-2}$ to $10^{2} \mathrm{~m}$, over length scales ranging from $10^{0}$ to $10^{3} \mathrm{~m}$ (Gelhar et al., 1992), and using Eq. (23) we obtain $P e \sim O(1)-O\left(10^{2}\right)$, indicating that both advection and diffusion are significant in the development of $[B]$ at the upper end of the range. Under this 
condition, advection and diffusion act on similar timescales and either Eq. (17) or Eq. (20) can be used.

It has been demonstrated that in porous media, when $P e \sim O(1)$, the progress of a reaction can be limited by incomplete mixing of flow paths containing the different reactants (e.g. $\mathrm{O}_{2}$ and $\mathrm{Fe}(\mathrm{II})$ ) (Cirpka and Attinger, 2003). Incomplete mixing results in a reduced exposure timescale (which is a function of the mixing frequency) and therefore the effectiveness of a reaction (or process) is diminished even though the processing timescale may be quite short or even instantaneous (Gramling et al., 2002). This highlights the need to accurately determine exposure timescales and the caution with which we should utilize spatially or temporally averaged exposure timescales.

\subsubsection{Regime III - hydrological disconnection}

When hydrological elements become hydrologically isolated with no water fluxes in or out, the chemical reaction shown in Eq. (6) may quickly become limited, by either the depletion of reactants or the build up of products. The consequences of hydrological/hydraulic isolation are no resupply of reactants and no flushing of products. Under these conditions, the change in concentration of $B$ cannot be described by Eq. (7), however to illustrate our conceptual framework we will assume that until chemical $B$ is $10 \%$ consumed, pseudo-first order kinetics can be utilized, i.e. the reaction is not limited by $[A]$. In this case we revert to using

$$
\frac{\partial[B]}{\partial t}=-k^{\prime}[B] .
$$

The general solution Eq. (3) can then be re-written simply as

$$
[B]_{t}=[\bar{B}]_{0} \exp \left(-k^{\prime} t\right)
$$

where $[\bar{B}]_{0}$ is the spatially averaged concentration of $B$ at $t=0$, and then

$N_{\mathrm{E}}^{\mathrm{I}}=\tau_{\mathrm{I}} k^{\prime}$.

\section{Discussion}

\subsection{Application of $N_{\mathrm{E}}$ approach across scales}

In the previous sections we outlined how $N_{E}$ and $P e$ can be used to characterise hydrological systems according to the fate of chemical $B$. We will now examine this concept across different temporal and spatial scales. We will focus on the oxidation of $\mathrm{Fe}(\mathrm{II})$, which plays a prominent role in linking metabolic activities across anaerobic and aerobic components of aquatic systems (Raiswell and Canfield, 2012). $\mathrm{Fe}$ (II) oxidation is an ecologically significant reaction both under neutral and acidic conditions, however the rate is strongly dependent on pH (Stumm and Morgan, 1996).
The oxidation process typically implies precipitation of ferric oxides and through that the generation of acidity. Under well-buffered conditions, such as anaerobic ground or pore waters, the $\mathrm{pH}$ remains relatively constant. Under low or no-alkalinity conditions however, oxidation of Fe(II) significantly contributes to acidification of surface waters. Examples of such systems are acidic mining lakes (Peine et al., 2000) or acid sulphate soils (Burton et al., 2006) where acidity has been generated through the oxidation of pyrite, but where acidic iron cycling, i.e. the combined reduction of ferric and oxidation of ferrous iron, maintains acidic conditions (Peine et al., 2000). Here we will compare anaerobic aquatic systems containing $\mathrm{Fe}(\mathrm{II})$ and how they respond to oxygen exposure under different transport regimes. We have chosen two $\mathrm{pH}$ conditions: neutral ( $\mathrm{pH} 7)$ conditions as found in many anaerobic environments, and slightly acidic $(\mathrm{pH} 4)$ conditions as found in many anaerobic systems receiving waters that have been exposed to pyrite oxidation (Blodau, 2006).

The oxidation of $\mathrm{Fe}(\mathrm{II})$ can be modelled using the rate law given by Stumm and Lee (1961).

$\frac{\mathrm{d}[\mathrm{Fe}(\mathrm{II})]}{\mathrm{d} t}=-k_{\mathrm{abio}} P_{\mathrm{O}_{2}}\left[\mathrm{OH}^{-}\right]^{2}[\mathrm{Fe}(\mathrm{II})]$

where $P_{\mathrm{O}_{2}}$ is the partial pressure of oxygen $(0.21 \mathrm{~atm})$ and $k_{\text {abio }}$ is the abiotic rate constant $\left(1.5 \times 10^{13} \mathrm{~L}^{2} \mathrm{~mol}^{-2}\right.$ $\mathrm{atm}^{-1} \mathrm{~min}^{-1}$ at $25^{\circ} \mathrm{C}$ ).

This rate law predicts extremely low oxidation rates under acidic conditions. Typically, $\mathrm{Fe}(\mathrm{II})$ oxidation will be accelerated by bacteria. Pesic et al. (1989) reported a decrease in microbial oxidation rate with increasing $\mathrm{pH}$ between $\mathrm{pH} 2.2$ and $\mathrm{pH}$ 3. Extrapolation of their rate law (Kirby et al., 1999) demonstrates that at $\mathrm{pH} 4$ the abiotic rate is still higher then the microbial rate. Hence, in our examination we will use Eq. (28) for $\mathrm{pH} 4$ and $\mathrm{pH} 7$. The rate constant $k$ in Eq. (28) can be converted into a pseudo 1st-order rate constant for ambient temperature and pressure conditions, and for a predefined $\mathrm{pH}$, as

$k^{\prime}=k_{\text {abio }} P_{\mathrm{O}_{2}}\left[\mathrm{OH}^{-}\right]^{2}$

where $k^{\prime}$ yields the reaction times, $\tau_{\mathrm{R}}=\tau_{\mathrm{P}}$ (Table 2), which will be used for the analyses below.

\subsubsection{Case I: porewater transport in deep lake sediments}

The sediment of deep eutrophic lakes $(\mathrm{pH}$ neutral conditions) or mining lakes (acidic conditions) may be hydrologically connected to the surrounding groundwater, but if the hydraulic conductivity of the sediment material is extremely low, groundwater inflow velocities could be $<10^{-9} \mathrm{~m} \mathrm{~s}^{-1}$. We assume a molecular diffusion coefficient, $D_{\text {eff }}$ of $10^{-9} \mathrm{~m}^{2} \mathrm{~s}^{-1}$.

Under this scenario, the characteristic length scale is not physically constrained. We can, however, estimate a depth at 
Table 2. Pseudo-first order rate constants, $k^{\prime}$, and processing (reaction) timescales, $\tau_{\mathrm{P}}$, for the oxidation of iron(II) under different $\mathrm{pH}$ conditions.

\begin{tabular}{lcc}
\hline $\mathrm{pH}$ & $k^{\prime}\left(\mathrm{min}^{-1}\right)$ & $\tau_{\mathrm{P}}(\mathrm{s})$ \\
\hline 7 & $3 \times 10^{-2}$ & $2 \times 10^{3}$ \\
4 & $3 \times 10^{-8}$ & $2 \times 10^{9}$ \\
\hline
\end{tabular}

which the $\mathrm{O}_{2}$ concentration has been decreased to a specified level. In order to fulfil the validity of pseudo-first order kinetics, we assume a reduction by only $10 \%$, i.e. $\Delta P_{\mathrm{O}_{2}}=0.021$ atm which corresponds to $\Delta\left[\mathrm{O}_{2}\right] \approx 0.03 \mathrm{mmol} \mathrm{L}^{-1}$ at ambient temperature, and stoichiometrically that corresponds to an $\mathrm{Fe}$ (II) consumption of $\Delta[\mathrm{FeII}]=0.03 \mathrm{mmol} \mathrm{L}^{-1}$. Hence, the thickness of a layer will be estimated, in which the oxygen concentration does not drop below $0.27 \mathrm{mmol} \mathrm{L}^{-1}$.

$\mathrm{Fe}$ (II) concentrations in $\mathrm{pH}$ neutral lake sediments rarely exceed $0.1 \mathrm{mmol} \mathrm{L}^{-1}$ (see e.g. Baccini, 1985; Gelhar et al., 1992), while in acidic environments $\mathrm{Fe}(\mathrm{II})$ concentrations of up to $10 \mathrm{mmol} \mathrm{L}^{-1}$ may be reached (Burton et al., 2006; Peine et al., 2000). Therefore, a $\Delta[\mathrm{FeII}]$ of $0.03 \mathrm{mmol} \mathrm{L}^{-1}$ is a $30 \%$ removal at $\mathrm{pH} 7$ and a $0.3 \%$ removal at $\mathrm{pH} 4$. Using Eq. (15), $N_{\mathrm{E}} \approx 0.4$ and 0.003 for $\mathrm{pH} 7$ and 4 , respectively.

In the next step we can estimate $\Delta x_{10 \%}$ by combining Eqs. (5) and (20) as

$\Delta x_{10 \%}=\sqrt{N_{\mathrm{E}}^{\mathrm{D}} \cdot \tau_{\mathrm{P}} \cdot D_{\mathrm{eff}}}$,

which yields $8 \times 10^{-4} \mathrm{~m}$ at $\mathrm{pH} 7$, and $8 \times 10^{-2} \mathrm{~m}$ at $\mathrm{pH} 4$. The corresponding exposure timescales, $\tau_{\mathrm{E}}^{\mathrm{D}}$, within these contact zones are $7 \times 10^{2} \mathrm{~s}$ at $\mathrm{pH} 7$, and $6 \times 10^{6} \mathrm{~s}$ at $\mathrm{pH} 4$. Using these length scales, a groundwater inflow velocity of $10^{-9} \mathrm{~m} \mathrm{~s}^{-1}$ and the molecular diffusion coefficient, $P e$, ranges from $8.2 \times 10^{-4}$ at $\mathrm{pH} 7$, to $7.6 \times 10^{-2}$ at $\mathrm{pH} 4$ (Table 3 ), which indicates diffusive conditions and supports application of Eq. (5).

The above calculations have two specific implications. Firstly, the thickness of the layer that remains close to $\mathrm{O}_{2}$ saturation varies significantly between the two $\mathrm{pH}$ regimes. The zone of $\mathrm{Fe}$ (II) production from dissimilatory iron reduction (a biogeochemical process sensitive to $\mathrm{O}_{2}$ ) will be shifted to deeper sediments under acidic conditions. Secondly and more importantly, the timescale of exposure to oxygen saturation is 4 orders of magnitudes longer under acidic conditions and lasts for several weeks. Note that the calculated $\tau_{\mathrm{E}}$ is a lower estimate and may be even longer at lower Fe(II) concentrations. This long timescale provides ample opportunities for interference from other biogeochemical processes that involve oxygen or consume $\mathrm{Fe}(\mathrm{II})$.

Hence, $N_{\mathrm{E}}$ can be regarded as a process-specific parameter that allows us to characterise hydrological systems based on chemical fate. When $N_{\mathrm{E}} \sim \mathrm{O}(1)$, as was calculated under $\mathrm{pH} 7$, the balance between exposure and processing is
Table 3. Estimates of relevant parameters and non-dimensional numbers at $\mathrm{pH} 4$ and 7.

\begin{tabular}{cclccc}
\hline $\mathrm{pH}$ & $\begin{array}{c}\mathrm{Fe}(\mathrm{II}) \text { in } \\
\text { porewater } \\
\left(\mathrm{mmol} \mathrm{L}^{-1}\right)\end{array}$ & $N_{\mathrm{E}}$ & $\Delta x_{10 \%}(\mathrm{~m})$ & $\tau_{\mathrm{E}}(\mathrm{s})$ & $P e$ \\
\hline 7 & 0.1 & 0.4 & $8 \times 10^{-4}$ & $7 \times 10^{2}$ & $8.2 \times 10^{-4}$ \\
4 & 10 & 0.003 & $8 \times 10^{-2}$ & $6 \times 10^{6}$ & $7.6 \times 10^{-2}$ \\
\hline
\end{tabular}

critical and the system will be sensitive to shifts in hydrological regime. When $N_{\mathrm{E}} \ll O(1)$, as was calculated under $\mathrm{pH} 4$, the system will not be sensitive to shifts in hydrological regime.

\subsubsection{Case II: Surface water - groundwater exchange}

The advective recharge of oxygenated surface waters into $\mathrm{Fe}(\mathrm{II})$-rich groundwater is very common in many riparian systems under losing conditions. While the majority of these systems are $\mathrm{pH}$ neutral, wetlands affected by acid sulphate soils (Johnston et al., 2011) and mining lakes (Fleckenstein et al., 2009) may lose acidic water to groundwater.

Again under this scenario, the characteristic length scale is not physically constrained, and we can again estimate the length scales over which the $\mathrm{O}_{2}$ concentration has been decreased by $10 \%$. The Fe(II) boundary conditions are selected as in Case I. $\Delta x_{10 \%}$ can now be calculated using Eqs. (4) and (17) as

$\Delta x_{10 \%}=u_{x} \tau_{\mathrm{P}} N_{\mathrm{E}}^{\mathrm{A}}$

where $u_{x}$ is set to $10^{-5} \mathrm{~m} \mathrm{~s}^{-1}$ for this scenario.

The distance from the riparian zone over which $10 \%$ of $\mathrm{O}_{2}$ is consumed is $6.8 \times 10^{-3} \mathrm{~m}$ at $\mathrm{pH} 7$, and $5.7 \times 10^{1} \mathrm{~m}$ at $\mathrm{pH}$ 4. In other words, after $57 \mathrm{~m}$ of flow across a riparian zone at $\mathrm{pH} 4$ the system would still be close to oxygen saturation, allowing $\mathrm{O}_{2}$ consuming reactions.

To calculate $P e$ numbers for Case II, we can use Eq. (23). In porous-media flow, $D_{\text {eff }}$ becomes a scale-dependent dispersion coefficient, which can be estimated from the dispersivity, $\alpha$, of the aquifer into which the lake water penetrates (see Eqs. 22 and 24). We get $\alpha_{i}=1 \times 10^{-5} \mathrm{~m}$ and $D_{\text {eff }}=1 \times 10^{-10} \mathrm{~m}^{2} \mathrm{~s}^{-1}$ for $\mathrm{pH} 7$, and $\alpha_{i}=6.4 \mathrm{~m}$ and $D_{\text {eff }}=6 \times 10^{-5} \mathrm{~m}^{2} \mathrm{~s}^{-1}$ for $\mathrm{pH}$ 4. Thus at $\mathrm{pH} 7$, i.e. within the short distance of $6 \mathrm{~mm}$, no dispersion occurs. The corresponding $P e$ ranges from $5.7 \times 10^{2}$ at $\mathrm{pH} 7$ (indicating advective transport through the $\mathrm{O}_{2}$ containing layer) to 8.9 at $\mathrm{pH} 4$ (indicating advective transport with contributions from dispersive mixing).

Equations (30) and (31) can be directly applied for water management purposes. For example, we propose that the width of a riparian zone, in which no agricultural activity is allowed, can be calculated using the framework presented here to ensure minimal nitrate export from groundwater to the river. With knowledge of the dominant transport 
conditions (and how they vary with time), we could size the riparian width to the length scale, $\Delta x$, that is required to remove, for instance, $90 \%$ of the nitrate that has infiltrated to groundwater from agricultural land. To some extent the "50day line" typically applied to constrain drinking water zones implicitly uses this concept already.

\subsubsection{Case III: temporarily disconnected systems}

Floodplain wetlands and playas frequently become temporarily disconnected from surface and sub-surface water flow pathways. In Western Australia, shallow groundwater-fed wetlands affected by acid sulphate soils fill with $\mathrm{Fe}(\mathrm{II})$-rich groundwater, which is then exposed to $\mathrm{O}_{2}$ (Nath et al., 2013). Seasonal lowering of the groundwater table disconnects the wetlands from the source of $\mathrm{Fe}(\mathrm{II})$, and its subsequent oxidation via ongoing exposure to $\mathrm{O}_{2}$ is controlled by the isolation timescale, i.e. $\tau_{\mathrm{E}}^{\mathrm{I}}$. Depending on the buffering capacity of the wetland mineralogy, both acidic and neutral conditions can be observed.

Under this scenario, the characteristic length and timescales are physically constrained. If we assume a typical $\tau_{\mathrm{E}}^{\mathrm{I}} \sim 100$ days $\left(\sim 10^{7} \mathrm{~s}\right)$, then using Eq. (14), we estimate the extent of $\mathrm{Fe}(\mathrm{II})$ oxidation as $100 \%$ at $\mathrm{pH} 7$ and $1 \%$ at $\mathrm{pH} 4$. The differences between $\mathrm{Fe}$ (II) oxidation at the different pHs can also be demonstrated by $N_{\mathrm{E}}$. Using Eq. (13), $N_{\mathrm{E}}$ is $5 \times 10^{3}$ at $\mathrm{pH} 7$ (indicating the disconnection timescale provides sufficient exposure opportunity for the reaction to proceed) and $5 \times 10^{-3}$ at $\mathrm{pH} 4$ (indicating that the disconnection timescale does not provide enough time for the reaction to proceed). Of course these calculations assume the wetland waters are fully mixing at all times. Any density stratification within the wetland will reduce $\tau_{\mathrm{E}}^{\mathrm{I}}$, i.e. the timescales over which $\mathrm{Fe}$ (II)-rich bottom waters are exposed to $\mathrm{O}_{2}$-rich surface waters. Density stratification may also alter the control volume utilized and therefore the spatial averaging of chemical concentrations.

\subsection{Competiveness of reactions}

We have shown that $N_{\mathrm{E}}$ numbers are reaction specific; the corresponding spatial scales are also reaction dependent and not always controlled by geomorphology. In a first approach, we can therefore argue that low $N_{\mathrm{E}}$ for a certain reaction implies ample opportunity for alternative reaction pathways to proceed between materially connected elements or within a materially isolated element. Inversely, high $N_{\mathrm{E}}$ implies predominance of the biogeochemical process of interest. $N_{\mathrm{E}}$ allows us to compare the effectiveness of different material processing reactions across a certain temporal $\left(\tau_{\mathrm{E}}\right)$ or spatial $(\Delta x)$ scale.

More generally, lower $N_{\mathrm{E}}$ implies lower competiveness of a specific reaction. In the examples discussed above, the oxidation of $\mathrm{Fe}$ (II) is much more competitive at $\mathrm{pH} 7$ than at $\mathrm{pH} 4$. In this case competiveness is clearly controlled by the large differences in $k^{\prime}$. However, $N_{\mathrm{E}}$ is of course also affected by the exposure timescale. We therefore propose that for a given system, $N_{\mathrm{E}}$ can be used as a general parameter to compare competiveness between different reactions of interest.

Competiveness of redox reactions is typically discussed in terms of thermodynamic arguments, for example the gain in free energy, $\Delta G_{\mathrm{f}}$, obtained from oxidation of organic matter (Zehnder and Stumm, 1988). This concept works very well in diffusion controlled systems such as the sediment porewaters of the ocean or deep lakes. Attempts to adapt this concept to groundwater systems have been problematic. Rather, zones of intensive redox activity are observed to be spatially distributed or located at plume fringes (see e.g. Prommer et al., 2006). Considering that the rate of a reaction is proportional to $\Delta G_{\mathrm{f}}$, thermodynamics are also related to the reaction timescale. Considering further that all dissolved substances have appropriately the same diffusion coefficients and that their residence times under diffusion controlled conditions are approximately identical, then it becomes clear that $\Delta G_{\mathrm{f}}$ and $N_{\mathrm{E}}$ are interrelated predictors for competiveness under diffusion-controlled (or well-mixed) conditions.

Under advection or dispersion controlled conditions, however, the timescale of exposure along a flow path varies strongly depending on external forcing. Of course the flow paths and therefore exposure timescales may be distributed in space, similar to residence times, and this spatial variability will give rise to a patchwork of $N_{\mathrm{E}}$ values, paralleling the concept of "residence time distributions" with each controlled by specific biogeochemical regimes. Under these conditions, chemical competiveness becomes dependent on the ratio of processing/reaction to exposure timescales; $N_{\mathrm{E}}$ therefore can be used as a general parameter to compare competiveness under all regimes.

\subsection{Intermittent connectivity and ecological consequences}

Hydrological systems transition between the regimes outlined above, according to external forcing. Of particular relevance may be shifts between Regime I and II or intermittent transition from Regime III, i.e. the disconnected state, to Regime I or II. Estimates of $N_{\mathrm{E}}$ for the different regimes provide a framework for predicting the biogeochemical and ecological significance of the shifts (Table 4).

As an example, riparian zones are frequently characterised by such regime shifts. Material connectivity between receiving streams and adjacent riparian soils or wetlands is often strongly related to storm events leading to rapid activation of groundwater and its discharge into streams. This is an example of systems that routinely shift between periods characterised by long exposure times and diffusion-controlled transport (Regime I), and periods triggered by rainfall events and characterised by strong advection and short exposure times (Regime II). This shift in regime results in substantial transfer of solutes, e.g. DOC, $\mathrm{Fe}, \mathrm{NO}_{3}^{-}$or other species. 
Table 4. A summary of system characteristics under the different regimes and as a function of $N_{\mathrm{E}}$. Note that once elements become connected after a period of isolation, it is possible for them to rapidly move across regimes. The balance between exposure timescales (both connected and isolated) and processing timescales determines the ecological signficance of the period of isolation and the regime shift.

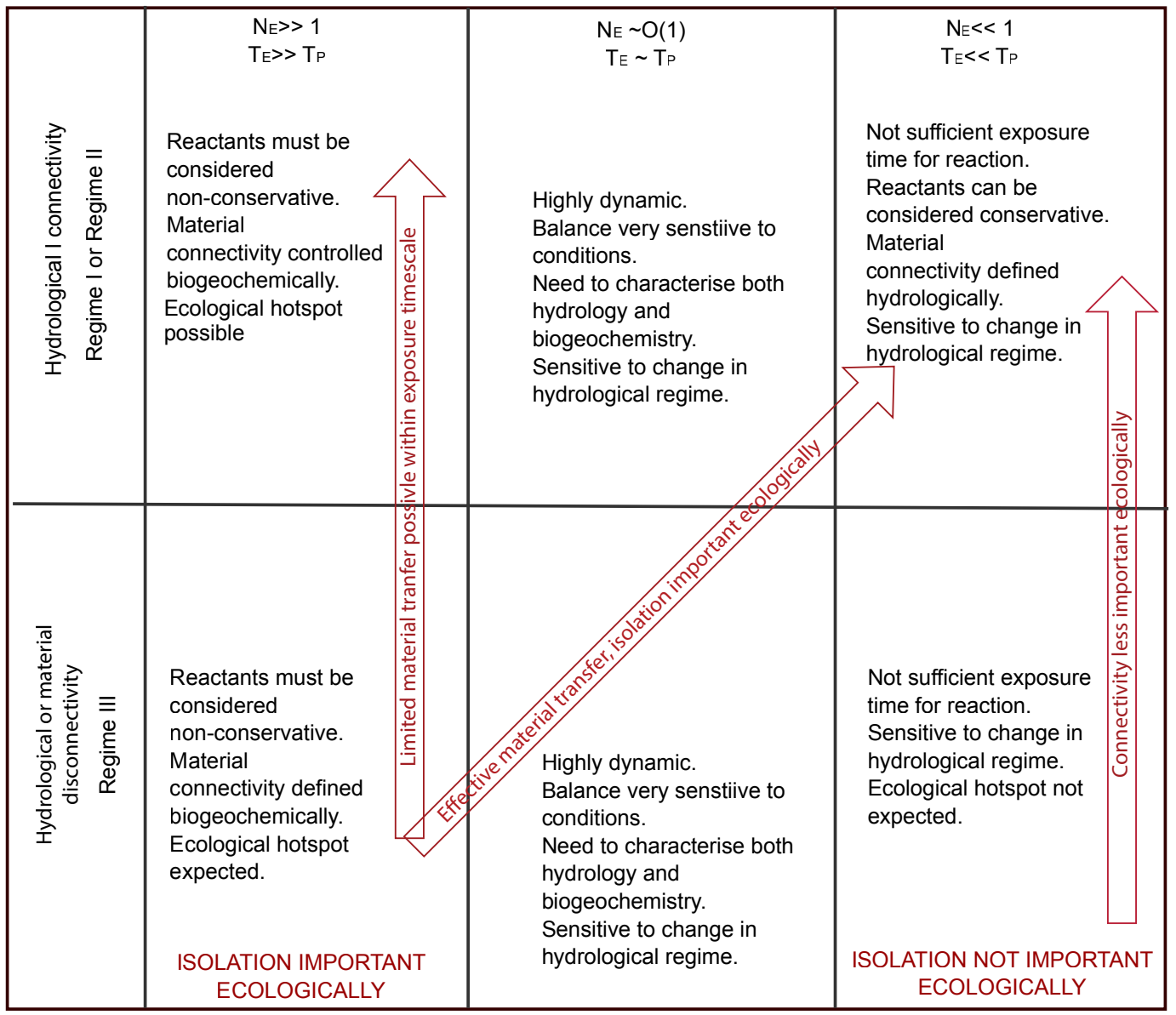

The magnitude of such pulses typically depends strongly on the antecedent conditions (e.g. Inamdar et al., 2004). Knorr (2013) observed that Fe and DOC were exported to streams during rainfall events only if the preceding period allowed a pool of Fe and DOC to be created (Regime I). Inversely, after a rainfall event, a rapid transfer of Fe to the stream would require the prevention of oxidation and retention at the site (Regime II). If we apply the $N_{\mathrm{E}}$ framework to this example, we can see that if the Regime I (pre-event) $N_{\mathrm{E}}$ for the formation of $\mathrm{Fe}$ (II) is high, a large pool of dissolved Fe can build up. In contrast, effective transfer of Fe into the receiving stream during a rainfall event requires the $\mathrm{Fe}(\mathrm{II})$ oxidation timescale to be longer than the (typically short) exposure timescale, i.e. $N_{\mathrm{E}}<1$. As in our case studies, the oxidation timescale depends strongly on $\mathrm{pH}$. The oxidation kinetics may also be dependent on DOC-Fe(II) complexation which stabilizes Fe(III) as colloids and thus promotes export of Fe associated with DOC (Llang et al., 1993). During periods of shifting exposure times, changes in $N_{\mathrm{E}}$ usefully highlight the different controls on material connectivity across a hydrological system and its impact on material transfer out of the system.

An interesting example for our discussion of material connectivity is given by Basu et al. (2011b) in an exploration of hydrological versus biogeochemical controls on the catchment scale, which can be reanalysed using $N_{\mathrm{E}}$ numbers. Basu et al. (2011b) termed export of substances from a catchment "chemostatic", (it showed little variation of concentration with flow) if the rate of mass input from storage areas was comparable to the rates of degradation. Under these conditions the storage pool does not become depleted and the concentration of the substance becomes buffered. Using our framework at the catchment scale, chemostatically behaving substances (nitrogen, weathering products) have $N_{\mathrm{E}} \sim 1$. In contrast, episodic (event driven) responses are predicted to occur if degradation rates of substances (e.g. pesticides) are high during periods of hydrological disconnection in the soil surface and prevent accumulation of these substances (Basu et al., 2011b). Using our framework, episodic events trigger material connectivity that transfers the substances into 
surface waters, and the transfer rate fluctuates with the size of the accumulated pool. For such episodic events, $N_{\mathrm{E}} \gg 1$ during time of disconnection in the soil surface, and $N_{\mathrm{E}} \ll 1$ at the catchment scale, allowing detection of the substance during subsequent connection.

Gradients of $N_{\mathrm{E}}$ in either space or time may also be indicative of sinks or sources. When $N_{\mathrm{E}}$ for a specific process and a specific hydrological element is large relative to it neighbouring elements, a concentration gradient may be established and a "hotspot" of material processing formed. When $N_{\mathrm{E}}$ for an element is large relative to the preceding or subsequent conditions, a "hot moment" may form. We suggest that it is the shift in $N_{\mathrm{E}}$ that is critical for hot spot or hot moment formation, rather than a regime shift. Some of the possible ecological consequences of shifts in $N_{\mathrm{E}}$ are explored in Table 4.

So far we have constrained ourselves to considering specific biogeochemical reactions occurring within elements of the hydrological cycle. Finally, we broaden our focus to consider landscape-scale ecological processes and their characteristic timescales. The extent to which an ecosystem is resilient to environmental perturbations is likely controlled by the relative rates at which a biological community can respond to environmental change or disturbance (i.e. $k^{\prime}$ ) and the exposure timescale of the relevant element. If we set the biogeochemical rate, $k^{\prime}$, to be analogous to population growth rate and the exposure timescale, $\tau_{\mathrm{E}}$, to be analogous to exogenous timescales (Hastings, 2010) or the reciprocal of the disturbance frequency, then our two timescales have direct analogues to concepts in terrestrial ecology. For example, Huston (1994) suggested that the ratio of the population growth rate to the disturbance frequency, i.e. $N_{\mathrm{E}}$ in our framework, impacts on biodiversity and ecological resilience (Fig. 6).

Of particular interest is the conceptual understanding that community biodiversity is maximal when there is a balance between population growth rate (or biogeochemical reaction rate) and disturbance frequency, i.e. when $N_{\mathrm{E}} \sim O(1)$ (Huston, 1994, Fig. 6). The biodiversity in turn affects ecosystem resilience (Gunderson, 2000; Scheffer and Carpenter, 2003); however, the stability space within which ecosystem resilience operates is determined by external factors, and has been related to characteristic spatial or temporal scales of external forcing (Scheffer and Carpenter, 2003). We have shown above that $N_{\mathrm{E}}$ is process-specific so the question arises whether we can describe the resilience of a system in terms of its $N_{\mathrm{E}}$ distribution. This requires further investigation.

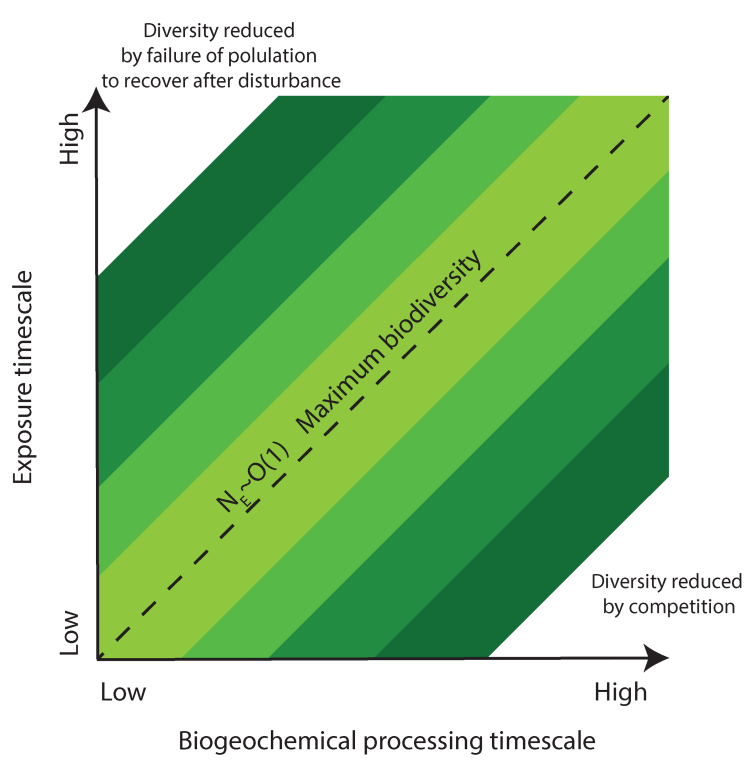

Fig. 6. The relationship between $N_{\mathrm{E}}$ and biodiversity. This is likely to hold true for microbial diversity as well as landscape-scale biodiversity. Modified from Huston (1994).

\section{Conclusions}

The concepts discussed above provide a general and holistic framework to analyse and characterise system behaviour in terms of the effectiveness of material processing, defined by the non-dimensional number $N_{\mathrm{E}}$, as the ratio of the exposure timescale to the material processing timescale. The use of this framework has multiple benefits: (a) it focuses our attention on clearly defining our system, its spatial scales and the material processing (or reaction) of interest; (b) it highlights that "transport limitation" is a relative concept and depends on the material processing of interest; (c) it allows us to incorporate isolated systems within a hydrological systems understanding; (d) it provides insights into the likely ecological significance of shifts in hydrological forcing; (e) it can be used for clarification of whether the balance in controlling mechanisms is constant with scale-up; (f) it can be used for water management as it allows us to appropriately size water remediation options; and (g) it can be used in the design of monitoring programs to ensure that monitoring scales capture the key dynamics of a system.

The $N_{\mathrm{E}}$ framework is simple in definition but challenging to apply. Identification of appropriate exposure and processing timescales for the system of interest is not trivial. Application of the $N_{\mathrm{E}}$ framework requires a clear definition of the problem and a sound rationale for the choice of timescales and the methods used for their determination. These methods can range from numerical simulations to geochemical or isotopic analysis. The $N_{\mathrm{E}}$ framework certainly helps to constrain a research problem, and we expect that, with on-going use and development of this framework by the scientific 
Appendix A

Notation.

\begin{tabular}{|c|c|c|}
\hline Variable & Units & Description \\
\hline$\alpha_{i}$ & $\mathrm{~m}$ & Dispersivity in $i$-direction \\
\hline$\alpha_{n}$ & dimensionless & Fourier cosine coefficient \\
\hline$\beta_{n}$ & dimensionless & Fourier sine coefficient \\
\hline$[B]$ & $\mathrm{mmol} \mathrm{L}^{-1}$ & Concentration of chemical $B$ \\
\hline$[B]_{\max }$ & $\mathrm{mmol} \mathrm{L}^{-1}$ & Maximum expected concentration of chemical $B$ \\
\hline$[B]_{0}$ & $\mathrm{mmol} \mathrm{L}^{-1}$ & Initial concentration of chemical $B$ \\
\hline$D a$ & dimensionless & Damköhler number \\
\hline$D_{\text {eff }}$ & $\mathrm{m}^{2} \mathrm{day}^{-1}$ & Effective diffusion coefficient \\
\hline$k^{\prime}$ & $\mathrm{s}^{-1}+\mathrm{s}^{-1}$ & First order rate constant \\
\hline$k_{\text {abio }}$ & $\mathrm{L}^{2} \mathrm{~mol}^{-2} \mathrm{~atm}^{-1} \min ^{-1}$ & Abiotic rate constant for iron oxidation \\
\hline$n$ & dimensionless & Summation index \\
\hline$N_{\mathrm{E}}$ & dimensionless & Ratio of exposure to processing timescales \\
\hline$N_{\mathrm{E}}^{\mathrm{A}}$ & dimensionless & Ratio of exposure to processing timescales (advective regime) \\
\hline$N_{\mathrm{E}}^{\mathrm{D}}$ & dimensionless & Ratio of exposure to processing timescales (diffusive regime) \\
\hline$N_{\mathrm{E}}^{\mathrm{I}}$ & dimensionless & Ratio of exposure to processing timescales (isolated regime) \\
\hline$P e^{\mathrm{L}}$ & dimensionless & Peclet number \\
\hline$P_{\mathrm{O}_{2}}$ & atm & Partial pressure of oxygen \\
\hline$q_{\max }$ & $\mathrm{mmol} \mathrm{L}^{-1}$ day $^{-1}$ & \\
\hline$t$ & unit of time & Time \\
\hline$\tau_{\mathrm{T}}$ & unit of time & Transport timescale \\
\hline$\tau_{\mathrm{R}}$ & unit of time & Reaction timescale \\
\hline$\tau_{\mathrm{F}}^{\mathrm{A}}$ & unit of time & Characteristic exposure timescale (asdvective regime) \\
\hline$\tau_{\mathrm{E}}^{\mathrm{D}}$ & unit of time & Characteristic exposure timescale (diffusive regime) \\
\hline$\tau_{\mathrm{E}}^{\mathrm{I}}$ & unit of time & Characteristic exposure timescale (isolated regime) \\
\hline$\tau_{\mathrm{P}}^{\mathrm{L}}$ & unit of time & Characteristic processing timescale \\
\hline$u_{i}$ & $\mathrm{~m} \mathrm{day}^{-1}$ & Velocity in $i$-direction \\
\hline$u_{x}$ & $\mathrm{~m}_{\text {day }}-1$ & Velocity in $x$-direction \\
\hline$x_{i}$ & $\mathrm{~m}$ & Distance in $i$-direction \\
\hline$\Delta x$ & $\mathrm{~m}$ & Characteristic length scale in $x$-direction \\
\hline$\Delta x_{10 \%}$ & $\mathrm{~m}$ & Characteristic length scale required for $10 \%$ of reactant to be removed \\
\hline
\end{tabular}

community, protocols for the delineation of timescales will develop.

This work has opened up an array of questions but perhaps the most intriguing question is how we most effectively analyse intermittently disconnected systems. Is it preferrable to take a stochastic approach, using an ensemble of exposure timescales? The parameter analysed could vary depending on assessed ecological significance, but could involve (a) the isolation timescales, (b) the connection timescales, and/or (c) the ratio of the isolation to connection timescales.

We expect that in many systems there will also be an ensemble of reaction timescales, so a pdf would also be required. We also expect the exposure timescales to have significantly greater variance than the reaction timescales. The ratio of these two pdfs would create an $N_{\mathrm{E}}$ pdf, which would in turn characterise material connectivity between systems. A full exploration of the stochastic nature of $N_{\mathrm{E}}$ is needed and requires analysis of multiple exemplar data sets.
Acknowledgements. The authors would like to express thanks to a large number of people who over the years have contributed to lively discussion on the use of $\mathrm{Da}$ and other non-dimensionless numbers for characterising catchments, including Carlos Ocampo, Murugesu Sivapalan, Jeff McDonnell, Paul Lavery, Ursula Salmon and Wolfgang Kurtz. This collaboration was supported by DFG grant Pe 438/20-1.

Edited by: S. Thompson

\section{References}

Ali, G. A. and Roy, A. G.: Shopping for hydrologically representative connectivity metrics in a humid temperate forested catchment, Water Resour. Res., 46, 1-24, doi:10.1029/2010WR009442, 2010.

Asarita, G.: Mass transfer and chemical reactions, Elsevier, Amsterdam, 1967. 
Baccini, P.: Phosphate interactions at the sediment-water interface, in: Chemical Processes in Lakes, edited by: Stumm, W., Wiley Online Library, 1985.

Basu, N. B., Rao, P. S. C., Thompson, S. E., Loukinova, N. V., Donner, S. D., Ye, S., and Sivapalan, M.: Spatiotemporal averaging of in-stream solute removal dynamics, Water Resour. Res., 47, W00J06, doi:10.1029/2010WR010196, 2011a.

Basu, N. B., Thompson, S. E., and Rao, P. S. C.: Hydrologic and biogeochemical functioning of intensively managed catchments: A synthesis of top-down analyses, Water Resour. Res., 47, W00J15, doi:10.1029/2011WR010800, 2011 b.

Battiato, I. and Tartakovsky, D. M.: Applicability regimes for macroscopic models of reactive transport in porous media, J. Contam. Hydrol., 120-121, 18-26, doi:10.1016/j.jconhyd.2010.05.005, 2011.

Beven, K. J.: Rainfall-runoff modelling: The primer, Wiley, New York, 2001.

Blodau, C.: A review of acidity generation and consumption in acidic coal mine lakes and their watersheds, Sci. Total Environ., 369, 307-332, 2006.

Bolster, D., de Anna, P., Benson, D. A., and Tartakovsky, A. M.: Incomplete mixing and reactions with fractional dispersion, Adv. Water Resour., 37, 86-93, doi:10.1016/j.advwatres.2011.11.005, 2012.

Botter, G., Bertuzzo, E., and Rinaldo, A.: Transport in the hydrologic response: Travel time distributions, soil moisture dynamics, and the old water paradox, Water Resour. Res., 46, 1-18, doi:10.1029/2009WR008371, 2010.

Botter, G., Bertuzzo, E., and Rinaldo, A.: Catchment residence and travel time distributions: The master equation, Geophys. Res. Lett., 38, 1-6, doi:10.1029/2011GL047666, 2011.

Burton, E., Bush, R., and Sullivan, L.: Sedimentary iron geochemistry in acidic waterways associated with coastal lowland acid sulfate soils, Geochim. Cosmochim. Acta, 79, 5455-5468, 2006.

Carleton, J. N.: Damkohler number distributions and constituent removal in treatment wetlands, Ecol. Eng., 19, 233-248, 2002.

Cirpka, O. A. and Attinger, S.: Effective dispersion in heterogeneous media under random transient flow conditions, Water Resour. Res., 39, 1-15, doi:10.1029/2002WR001931, 2003.

Dankwerts, P. V.: Absorption by simultaneous diffusion and chemical reaction into particles of various shapes and into falling drops, Trans. Faraday Soc., 47, 1014-1023, 1951.

Detty, J. M. and McGuire, K. J.: Topographic controls on shallow groundwater dynamics: implications of hydrologic connectivity between hillslopes and riparian zones in a till mantled catchment, Hydrol. Process., 24, 2222-2236, doi:10.1002/hyp.7656, 2010.

Dooge, J. C. I.: Looking for hydrologic laws, Water Resour. Res., 22, 46-58, 1986.

Fleckenstein, J., Neumann, C., Volze, N., and Beer, J.: Raumzeitmuster des Grundwasser-Seeaustausches in einem Tagebaurestsee, Grundwasser, 14, 207-217, 2009.

Gelhar, L. W. L., Welty, C., and Rehfeldt, K. R. K.: A critical review of data on field-scale dispersion in aquifers, Water Resour. Res., 28, 1955-1974, 1992.

Gramling, C. M., Harvey, C. F., and Meigs, L. C.: Reactive transport in porous media: a comparison of model prediction with laboratory visualization, Environ. Sci. Technol., 36, 2508-2514, 2002.

Gunderson, L. H.: Ecological resilience - in theory and application, Annu. Rev. Ecol. Syst., 31, 425-439, 2000.
Hastings, A.: Timescales, dynamics and ecological understanding, Ecology, 91, 3471-3480, 2010.

Hornberger, G. M., Scanlon, T. M., and Raffensperger, J. P.: Modelling transport of dissolved silica in a forested headwater catchment: the effect of hydrological and chemical time scales on hysteresis in the concentration-discharge relationship, Hydrol. Process., 15, 2029-2038, doi:10.1002/hyp.254, 2001.

Hrachowitz, M., Soulsby, C., Tetzlaff, D., Malcolm, I. A., and Schoups, G.: Gamma distribution models for transit time estimation in catchments: Physical interpretation of parameters and implications for time-variant transit time assessment, Water Resour. Res., 46, doi:10.1029/2010WR009148, 2010.

Huston, M. A.: Biological diversity: The coexistence of species on changing landscapes, Cambridge University Press, Cambridge, 1994.

Inamdar, S. P., Christopher, S. F., and Mitchell, M. J.: Export mechanisms for dissolved organic carbon and nitrate during summer storm events in a glaciated forested catchment in New York, USA, Hydrol. Process., 18, 2651-2661, doi:10.1002/hyp.5572, 2004.

Johnston, S., Keene, A., Bush, R., Sullivan, L., and Wong, V.: Tidally driven water column hydro-geochemistry in a remediating acidic wetland, J. Hydrol., 409, 128-139, 2011.

Kirby, C., Thomas, H., Southam, G., and Donald, R.: Relative contributions of abiotic and biological factors in Fe(II) oxidation in mine drainage, Appl. Geochem., 14, 511-530, 1999.

Klein, C., Wilson, K., Watts, M., Stein, J., Berry, S., Carwardine, J., Smith, M. S., Mackey, B., and Possingham, H.: Incorporating ecological and evolutionary processes into continental-scale conservation planning, Ecol. Appl., 19, 206-217, 2009.

Knorr, K.-H.: DOC-dynamics in a small headwater catchment as driven by redox fluctuations and hydrological flow paths - are DOC exports mediated by iron reduction/oxidation cycles?, Biogeosciences, 10, 891-904, doi:10.5194/bg-10-891-2013, 2013.

Kurtz, W., and Peiffer, S.: The role of transport in aquatic redox chemistry, in: Aquatic Redox Chemistry, edited by: Tratnyek,P. G., Grundl, T. J., and Haderlein, S. B., American Chemical Society, Washington DC, USA, 559-580, 2011.

Llang, L., McNabb, J. A., Paulk, J. M., Guy, B., and McCarthy, J. F.: Kinetics of $\mathrm{Fe}(\mathrm{I} 1)$ oxygenation at low partial pressure of oxygen in the presence of natural organic matter, Environ. Sci. Technol., 27, 1864-1870, 1993.

McDonnell, J., McGuire, K., Aggarwal, P., Beven, K., Biondi, D., Destouni, G., Dunn, S., James, A., Kirchner, J., Kraft, P., Lyon, S., Maloszewski, P., Newman, B., Pfister, L., Rinaldo, A., Rodhe, A., Sayama, T., Seibert, J., Solomon, K., Soulsby, C., Stewart, M., Tetzlaff, D., Tobin, C., Troch, P., Weiler, M., Western, A., Wörman, A., and Wrede, S.: How old is streamwater? Open questions in catchment transit time conceptualization, modelling and analysis, Hydrol. Process., 24, 1745-1754, doi:10.1002/hyp.7796, 2010.

McDonnell, J., Sivapalan, M., Vaché, K., Dunn, S., Grant, G., Haggerty, R., Hinz, C., Hooper, R., Kirchner, J., Roderick, M., Selker, J., and Weiler, M.: Moving beyond heterogeneity and process complexity: A new vision for watershed hydrology, Water Resour. Res., 43, 1-6, doi:10.1029/2006WR005467, 2007.

McGuire, K. and McDonnell, J.: A review and evaluation of catchment transit time modeling, J. Hydrol., 330, 543-563, doi:10.1016/j.jhydrol.2006.04.020, 2006. 
Meerkerk, A. L., Van Wesemael, B., and Bellin, N.: Application of connectivity theory to model the impact of terrace failure on runoff in semi-arid catchments, Hydrol. Process., 23, 2792-2803, doi:10.1002/hyp.7376, 2009.

Michaelides, K. and Chappell, A.: Connectivity as a concept for characterising hydrological behaviour Definitions of Connectivity, Hydrol. Process., 522, 517-522, doi:10.1002/hyp.7214, 2009.

Michalak, A. and Kitanidis, P.: Macroscopic behavior and randomwalk particle tracking of kinetically sorbing solutes, Water Resour. Res., 36, 2133-2146, doi:10.1029/2000WR900109, 2000.

Nath, B., Lillicrap, A., Ellis, L., Boland, D., and Oldham, C.: Hydrological and chemical connectivity dynamics in a groundwater-dependent ecosystem impacted by acid sulfate soils, Water Resour. Res., 49, 441-457, doi:10.1029/2012WR012760, 2013.

Ocampo, C. J., Oldham, C. E., and Sivapalan, M.: Nitrate attenuation in agricultural catchments: Shifting balances between transport and reaction, Water Resour. Res., 42, 1-16, doi:10.1029/2004wr003773, 2006.

Opperman, J. J., Luster, R., McKenney, B. A., Roberts, M., and Meadows, A. W.: Ecologically Functional Floodplains: Connectivity, Flow Regime, and Scale, J. American Water Resour. Assoc., 46, 211-226, doi:10.1111/j.1752-1688.2010.00426.x, 2010.

Park, S. S. and Jaffe, P. R.: Development of a sediment redox potential model for the assessment of post-depositional metal mobility, Ecol. Model., 91, 169-181, 1995.

Peine, A., Tritschler, A., Kusel, K., and Peiffer, S.: Electron flow in an iron-rich acidic sediment - evidence for an acidity-driven iron cycle, Limnol. Oceanogr., 45, 1077-1087, 2000.

Pesic, B., Oliver, D., and Wichlacz, P. An electrochemical method of measuring the oxidation rate of ferrous to ferric iron with oxygen in the presence of Thiobacillus ferrooxidans, Biotechnol. Bioeng., 33, 428-439, 1989.

Pringle, C.: The need for a more predictive understanding of hydrologic connectivity, Aquat. Conserv., 13, 467-471, doi:10.1002/aqc.603, 2003a.

Pringle, C.: What is hydrologic connectivity and why is it ecologically important?, Hydrol. Process., 17, 2685-2689, doi:10.1002/hyp.5145, 2003b.

Prommer, H., Tuxen, N., and Bjerg, P.: Fringe-controlled natural attenuation of phenoxy acids in a landfill plume: integration of field-scale processes by reactive transport modeling, Environ. Sci. Technol., 40, 4732-4738, 2006.
Raiswell, R. and Canfield, D.: The iron biogeochemical cycle past and present, Geochem. Perspect., 1, 1-232, 2012.

Schäfer, D., Schäfer, W., and Kinzelbach, W.: Simulation of reactive processes related to biodegradation in aquifers 1 . Structure of the three-dimensional reactive transport model, J. Contam. Hydrol., 31, 167-186, 1998.

Scheffer, M. and Carpenter, S. R.: Catastrophic regime shifts in ecosystems: linking theory to observation, Trends Ecol. Evol., 18, 648-656, doi:10.1016/j.tree.2003.09.002, 2003.

Stumm, W. and Lee, G.: Oxygenation of Ferrous Iron, Indust. Eng. Chem. Res., 53, 143-146, 1961.

Stumm, W. and Morgan, J. J.: Aquatic chemistry: chemical equilibria and rates in natural waters, John Wiley \& Sons Inc., New York, USA, 1996.

Tetzlaff, D., Soulsby, C., Bacon, P. J., and Youngson, A. F.: Connectivity between landscapes and riverscapes - a unifying theme in integrating hydrology and ecology in catchment science?, Hydrol. Process., 1389, 1385-1389, 2007.

Thompson, S. E., Harman, C. J., Troch, P. A., Brooks, P. D., and Sivapalan, M.: Spatial scale dependence of ecohydrologically mediated water balance partitioning: A synthesis framework for catchment ecohydrology, Water Resour. Res., 47, 1-20, doi:10.1029/2010WR009998, 2011a.

Thompson, S. E., Basu, N. B., Lascurain, J., Aubeneau, A., and Rao, P. S. C.: Relative dominance of hydrologic versus biogeochemical factors on solute export across impact gradients, Water Resour. Res., 47, W00J05, doi:10.1029/2010WR009605, 2011 b.

Todd, D. and Mays, L.: Groundwater Hydrology, John Wiley \& Sons, Chichester, 2005.

Vaché, K. B. and McDonnell, J. J.: A process-based rejectionist framework for evaluating catchment runoff model structure, Water Resour. Res., 42, 1-15, doi:10.1029/2005WR004247, 2006.

Wehrer, M. and Totsche, K. U.: Detection of non-equilibrium contaminant release in soil columns: Delineation of experimental conditions by numerical simulations, J. Plant Nutr. Soil Sci., 166, 475-483, doi:10.1002/jpln.200321095, 2003.

Werner, T. M. and Kadlec, R. H.: Wetland residence time distribution modeling, Science, 15, 77-90, 2000.

Zehnder, A. and Stumm, W.: Geochemistry and biogeochemistry of anaerobic habitats, in: Biology of Anaerobic Organisms, edited by: Zehnder, A., Wiley, New York, 1-38, 1988. 